\title{
Influência da inoculação com bactérias endofíticas no desenvolvimento de plantas de milho
}

Objetivou-se neste trabalho avaliar o efeito de bactérias promotoras do crescimento vegetal na cultura do milho cv. DKB 390PRO2. Foram utilizadas estirpes de bactérias endofíticas isoladas de folhas, caules e raízes de Brachiaria brizantha: UBb01; UBb04; UBb05; UBb08; UBb11; UBb12; UBb15; UBb16; UBb18; UBb20. Foram conduzidos dois experimentos: 1- foi conduzido em câmara de crescimento com fotoperíodo e temperatura controlados (16 horas luz e 280 C, respectivamente), foram empregados tubetes de PVC e como substrato vermiculita esterilizada; 2 - conduzido em casa-de-vegetação, utilizando-se vasos de PVC preenchidos com terra: vermiculita (2:1). O delineamento experimental foi inteiramente casualizado com 12 repetições com os seguintes tratamentos: 1 testemunha absoluta (sem nitrogênio e sem inoculação); 2 - aplicação de nitrogênio (na forma de nitrato de potássio); 3 ) inoculação das sementes com as diferentes bactérias. Os inoculantes foram preparados meios líquidos tripticaseina soya e incubados a $350 \mathrm{C}$ por $72 \mathrm{~h}$. As sementes de milho foram submersas nas suspensões bacterianas (108 UFC mL-1) por 5 minutos, e em seguida semeadas. Os dados obtidos foram analisados pelo Teste de Kruskal Wallis para comparação dos tratamentos (bactérias) nas variáveis: comprimento parte aérea e raiz, fitomassa fresca da parte aérea, fitomassa seca da parte aérea e raiz, complementado com teste de comparações múltiplas de Dunn's. Verificou-se que em condições estéreis as estirpes UBb04, UBb05, UBb08, UBb12, UBb15, UBb16 promoveram o crescimento de plantas de milho; e as estirpes UBb04, UBb15, UBb16, em condições de casa de vegetação favoreceram o desenvolvimento das plantas de milho, superando inclusive as plantas que receberam nitrogênio.

\section{Influence of inoculation with endophytic bacteria in the development of corn plants}

The objective of this work was to evaluate the effect of plant growth promoter bacteria on corn cv. DKB 390PRO2. Endophytic bacteria strains isolated from leaves, stems and roots of Brachiaria brizantha were used: UBb01; UBb04; UBb05; UBb08; UBb11; UBb12; UBb15; UBb16; UBb18; UBb20. Two experiments were conducted: 1- was conducted in a growth chamber with controlled photoperiod and temperature (16 hours light and 280 C, respectively), using PVC tubes and as a sterilized vermiculite substrate; 2 - conducted in greenhouse, using PVC vessels filled with earth: vermiculite (2: 1). The experimental design was completely randomized with 12 replicates with the following treatments: 1 - absolute control (without nitrogen and without inoculation); 2 - application of nitrogen (in the form of potassium nitrate); 3) seed inoculation with the different bacteria. The inoculants were prepared tripticasein soy media and incubated at $35^{\circ} \mathrm{C}$ for $72 \mathrm{~h}$. Corn seeds were submerged in the bacterial suspensions ( $108 \mathrm{CFU} \mathrm{mL}-1)$ for 5 minutes, and then seeded. The data obtained were analyzed by Kruskal Wallis test to compare the treatments (bacteria) in the variables: shoot length and root, fresh shoot, fresh shoots and roots, complemented by Dunn's multiple comparisons test. Strains UBb04, UBb05, UBb08, UBb12, UBb15, UBb16 were found to undergo the growth of corn plants under sterile conditions; and strains UBb04, UBb15, UBb16, under greenhouse conditions favored the development of maize plants, surpassing even the plants that received nitrogen.

Keywords: Zea mays L; Plant growth promoting bacteria; Inoculation; Seeds; Phytomass.

Topic: Microbiologia Agrícola e Ambiental

Reviewed anonymously in the process of blind peer.
Received: $14 / 12 / 2017$

Approved: $24 / 01 / 2018$
Jader Cesar Batistela

Universidade Camilo Castelo Branco, Brasil

http://lattes.cnpq.br/0483620446870006

agrofertil77@yahoo.com.br

Dora Inés Kozusny-Andreani

Universidade Brasil, Brasil

http://lattes.cnpq.br/1260217332585007

doraines@terra.com.br

Roberto Andreani Junior

Universidade Brasil, Brasil

http://lattes.cnpq.br/5863157086821275

robertoandreani@uol.com.br

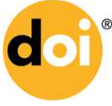

DOI: 10.6008/CBPC2179-6858.2018.002.0002
Referencing this:

BASTITELA, J. C.; KOZUSNY-ANDREANI, D. I.; ANREANI JUNIOR, R.. Influência da inoculação com bactérias endofíticas no desenvolvimento de plantas de milho. Revista Ibero Americana de Ciências Ambientais, v.9, n.2, p.11-18, 2018. DOI: http://doi.org/10.6008/CBPC2179-6858.2018.002.0002 


\section{INTRODUÇÃO}

Os micro-organismos são fonte de recursos naturais utilizados basicamente em todos os ramos de atividade, tais como, saúde, produção de alimentos e produção industrial entre outros, podendo ser estudados em ambientes naturais ou em ambientes de laboratório. É parte muito importante do ecossistema, devido seu papel de transformação de energia e participação em processos biogeoquímicos. Apesar do número elevado de micro-organismos conhecidos e descritos quanto sua importância, dados derivados de estudos comparativos indicam que uma pequena fração dos micro-organismos presentes na natureza, aproximadamente $1 \%$, pode ser cultivada por meio do emprego de métodos microbiológicos convencionais (MOREIRA et al., 2006).

Os micro-organismos são conhecidos como endófitos quando vivem ao menos por um período no interior de uma planta sem causar nenhum tipo de doença, epífitos aqueles que vivem na superfície das plantas e fitopatógenos que causam doenças as plantas. Há poucas informações referentes à base biológica das interações endófitos-plantas, no entanto são conhecidas as vantagens que estes micro-organismos oferecem quanto ao controle de pragas e de fitopatógenos; produção de metabólitos de interesse farmacológico; promoção do crescimento vegetal; vetores para a introdução de genes em plantas hospedeiras; fixação biológica de nitrogênio; produção de produtos biológicos evitando e reduzindo o uso de agroquímicos (MARIANO et al., 2000; RAMAMOORTHY, et al., 2001; NANDAKUMAR, et al., 2001; SCHLINDWEIN, et al., 2008; KOZUSNY-ANDREANI et al., 2014; BORACIN et al., 2016).

Na cultura do milho (Zea mays L.) foi verificado que ocorrem vantagens entre associação de raízes desta gramínea e bactérias presentes no solo, incluindo grupos de fixadores de nitrogênio e/ou promotores de crescimento, trazendo incrementos na produtividade (DIDONET et al., 2000; BOBATO, 2006; TORIBIOJIMÉNEZ et al., 2017). Há relatos de cepas de Azospirillum brasilense aumentando o rendimento de milho de $24 \%$ a 30 \%, em comparação com o controle não inoculado (HUNGRIA et al., 2010).

Estes micro-organismos promotores do crescimento tem se constituído nos últimos anos fonte de pesquisas na cultura do milho assim como em outras gramíneas (MOREIRA et al., 2006; SALA et al., 2007; FIGUEIREDO et al., 2008; LIMA et al., 2011). Objetivou-se neste trabalho avaliar o efeito de bactérias promotoras do crescimento vegetal na cultura do milho (Zea mays L) cv DKB 390 PRO2.

\section{METODOLOGIA}

\section{Local e condução dos experimentos}

O experimento foi desenvolvido no Laboratório de Biotecnologia e em casa-de-vegetação da Universidade Brasil, campus Fernandópolis, situado no município de Fernandópolis/SP, localizado a uma altitude de 535 metros e com as seguintes coordenadas geográficas, latitude 2017' 02" e longitude 50 14' 47". Foram utilizadas estirpes de bactérias endofíticas isoladas de folhas, caules e raízes de Brachiaria brizantha: UBb01; UBb04; UBb05; UBb08; UBb11; UBb12; UBb15; UBb16; UBb18; UBb20. A pesquisa foi 
desenvolvida em duas etapas: verificação inicial da eficiência das bactérias em bandejas e condução da cultura em vasos.

\section{Preparação da suspensão bacteriana e inoculação das sementes}

As bactérias selecionadas e purificadas foram utilizadas para inocular frascos contendo meios líquidos tripticaseina soya (TS) e NFb (DÖBEREINER et al., 1995). Após inoculação os frascos foram incubados a $35^{\circ} \mathrm{C}$ por $72 \mathrm{~h}$, sob agitação $(200 \mathrm{rpm})$. As suspensões bacterianas $\left(10^{8} \mathrm{UFC} \mathrm{mL} \mathrm{L}^{-1}\right.$, unidades formadoras de colônias) foram utilizadas para inocular as sementes de milho transgênico, que foram depositadas na solução e deixadas submersas no inoculante, por 5 minutos, passado este período as mesmas foram semeadas imediatamente.

\section{Avalição de promoção de crescimento pelas bactérias}

\section{Experimento 1}

Foi conduzido em câmara de crescimento com temperatura e foto período controlados $\left(28^{\circ} \mathrm{C}\right.$ e 16 horas luz, respectivamente), assim foram empregadas sementes de milho tranagênico cv DKB 390PRO2, tubetes de PVC e como substrato vermiculita esterilizada (figura 1).

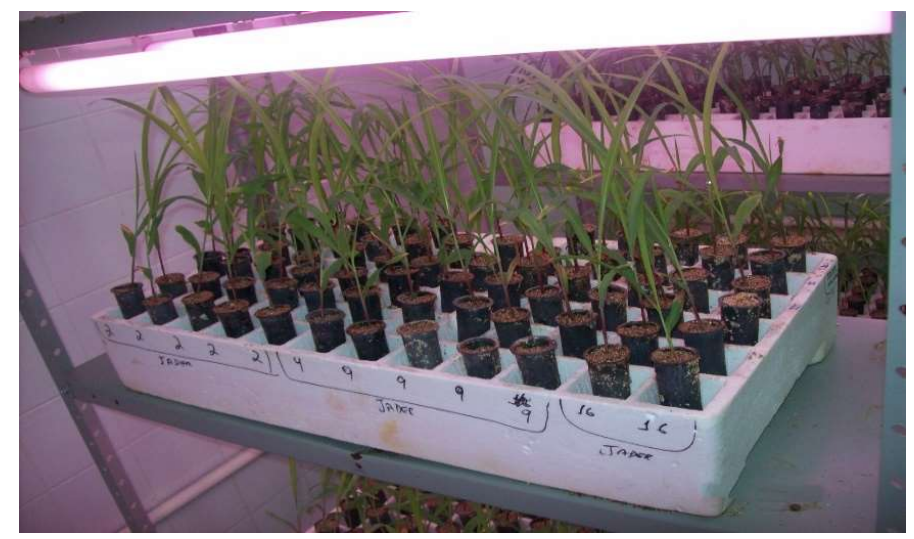

Figura 1: Vista do experimento conduzido em câmara de crescimento.

Prévio à semeadura o substrato foi irrigado com água deionizada esterilizada, as sementes já inoculadas foram depositadas e cobertas com o substrato. 0 delineamento experimental foi inteiramente casualizado com 12 repetições com os seguintes tratamentos: 1- testemunha absoluta (sem aplicação de nitrogênio e sem inoculação); 2- aplicação de nitrogênio (na forma de nitrato de potássio, 3 a 12) inoculação das sementes com as diferentes bactérias. O fornecimento de água foi realizado diariamente, empregandose água destilada esterilizada, e os nutrientes foram fornecidos semanalmente, utilizando-se solução nutritiva de Norris, isenta de nitrogênio (tabela 1), empregando-se por célula $10 \mathrm{~mL}$ em todos os tratamentos. No tratamento que requeria nitrogênio foram adicionados nitrato de potássio em concentração de $0,8 \%$.

O experimento foi conduzido até o estágio de cinco folhas e os dados obtidos foram tabulados para análise de resultados pelo Teste de Kruskal Wallis para comparação dos tratamentos (bactérias) nas variáveis comprimento parte aérea e raiz, fitomassa fresca da parte aérea, fitomassa seca da parte aérea e raiz, 
complementado com teste de comparações múltiplas de Dunn's. Foi empregada análise de variância paramétrica para comparar as bactérias na variável fitomassa fresca da raiz, o teste utilizado foi de comparação múltipla, Método de Tukey.

Tabela 1: Solução nutritiva de Norris utilizada como fonte de nutrientes.

\begin{tabular}{|c|c|}
\hline Reagentes & Quantidades dos reagentes* \\
\hline $\mathrm{CaSO}_{4} \cdot 2 \mathrm{H}_{2} \mathrm{O}$ & $34,40 \mathrm{~g} / \mathrm{L}$ \\
\hline $\mathrm{MgSO}_{4} \cdot 7 \mathrm{H}_{2} \mathrm{O}$ & $493 \mathrm{~g} / \mathrm{L}$ \\
\hline $\mathrm{KCL}$ & $149 \mathrm{~g} / \mathrm{L}$ \\
\hline $\mathrm{KH}_{2} \mathrm{PO}_{4}$ & $150 \mathrm{~g} / \mathrm{L}$ \\
\hline $\mathrm{K}_{2} \mathrm{HPO}_{4}$ & $50 \mathrm{~g} / \mathrm{L}$ \\
\hline $\mathrm{CuSO}_{4} \cdot 5 \mathrm{H}_{2} \mathrm{O}$ & $150 \mathrm{mg} / \mathrm{L}$ \\
\hline $\mathrm{ZnSO} 4.7 \mathrm{H}_{2} \mathrm{O}$ & $440 \mathrm{mg} / \mathrm{L}$ \\
\hline $\mathrm{MnSO}_{4} \cdot 2 \mathrm{H}_{2} \mathrm{O}$ & $400 \mathrm{mg} / \mathrm{L}$ \\
\hline$(\mathrm{NH} 4) 6 \mathrm{Mo}^{2} \mathrm{O}_{2} 4 \mathrm{H}_{2} \mathrm{O}$ & $20 \mathrm{mg} / \mathrm{L}$ \\
\hline $\mathrm{H}_{3} \mathrm{BO}_{3}$ & $1,43 \mathrm{~g} / \mathrm{L}$ \\
\hline $\mathrm{FeSO}_{4} \cdot 7 \mathrm{H}_{2} \mathrm{O}$ & $50 \mathrm{mg} / \mathrm{mL}$ \\
\hline Ácido Cítrico & $50 \mathrm{mg} / \mathrm{mL}$ \\
\hline
\end{tabular}

* Solução 10 vezes concentrada.

\section{Experimento 2}

Para realização do segundo experimento foram selecionadas as bactérias que apresentaram comportamento de promotoras de crescimento vegetal em condições estéreis (experimento 1). Empregaram-se vasos de PVC preenchidos com uma mistura de terra e vermiculita, na proporção de 2:1. 0 delineamento experimental foi inteiramente casualizado com 4 repetições com os seguintes tratamentos: 1testemunha absoluta (sem aplicação de nitrogênio e sem inoculação); 2- aplicação de nitrogênio (na forma de nitrato de potássio), 3 a 5- inoculação das sementes com as diferentes bactérias (UBb04; UBb15; UBb16). A preparação do inoculante e a inoculação das sementes seguiram os protocolos do primeiro experimento.

O fornecimento de água foi periódico e de acordo com as necessidades da planta, enquanto que os nutrientes foram fornecidos semanalmente $(100 \mathrm{~mL})$ por vaso. Após 90 dias, a plantas foram cuidadosamente colhidas e lavadas com água, procedendo-se a avalição a altura das plantas. Foram separadas a parte aérea das raízes e pesadas para obtenção da fitomassa fresca. Posteriormente foram acondicionadas em embalagem de papel e deixadas 48 horas em estufa com circulação de ar e temperatura constante a $56^{\circ} \mathrm{C}$ para obtenção da fitomassa seca.

Os dados obtidos foram tabulados para análise de resultados. Para as variáveis: comprimento das folhas e das raízes foi utilizada a técnica de análise de variância paramétrica com um fator, complementada com o teste de comparações múltiplas de Tukey. Já para as variáveis fitomassa fresca e seca das folhas e das raízes, foi utilizada a técnica de análise de variância não paramétrica de Kruskall Wallis, complementada pelo teste de comparação múltipla de Dunn, em todos os testes foi utilizado um nível de 5\% de significância.

\section{DISCUSSÃO TÉORICA}

\section{Experimento 1}

Na tabela 2 estão apresentados os resultados correspondentes ao comprimento e fitomassa fresca da arte aérea e raízes, fitomassa seca da parte aérea de plantas de milho transgênico cv DKB 390PRO2. Em 
relação ao comprimento da parte aérea, verificou-se que houveram diferenças estatísticas significativas entre os tratamentos, plantas que receberam inoculação com as estirpes UBb04, UBb05, UBb08, UBb12, UBb15, UBb16 e as que receberam $\mathrm{N}$ na forma de nitrato de potássio apresentaram desenvolvimento superior a aquelas que receberam inoculação com UBb01, UBb11, UBb12, UBb20. Não foram observadas diferenças entre os tratamentos quanto a fitomassa fresca da parte aérea, no entanto as plantas inoculadas com UBb01, UBb11 e UBb20 e as plantas testemunha apresentaram menor acúmulo de fitomassa seca (Tabela 2).

Tabela 2: Mediana, máximo e mínimo das variáveis comprimento e fitomassa fresca e seca da parte aérea e fitomassa seca da raiz de plantas de milho transgênico cv DKB 390PRO2, submetidas a diferentes tratamentos.

\begin{tabular}{|c|c|c|c|c|c|}
\hline \multirow[t]{2}{*}{ Tratamentos } & \multicolumn{5}{|l|}{ Variáveis } \\
\hline & $\begin{array}{l}\text { Comprimento parte } \\
\text { aérea }\end{array}$ & $\begin{array}{l}\text { Fitomassa fresca parte } \\
\text { aérea }\end{array}$ & $\begin{array}{l}\text { Fitomassa seca parte } \\
\text { aérea }\end{array}$ & Comprimento raiz & $\begin{array}{l}\text { Fitomassa seca } \\
\text { raiz }\end{array}$ \\
\hline $\begin{array}{l}\text { Testemunha } \mathrm{S} / \mathrm{N} \\
\mathrm{S} / \mathrm{I}\end{array}$ & $\begin{array}{l}35,00 \mathrm{c} \\
(40,7 ; 28,1)\end{array}$ & $\begin{array}{l}0,75 \mathrm{~b} \\
(1,01 ; 0,57)\end{array}$ & $\begin{array}{l}0,05 \mathrm{~b} \\
(0,10 ; 0,02)\end{array}$ & $\begin{array}{l}16,50 \mathrm{~b} \\
(21,5 ; 12,2)\end{array}$ & $\begin{array}{l}0,05 \mathrm{~b} \\
(0,09 ; 0,01)\end{array}$ \\
\hline C/N S/I & $\begin{array}{l}45,20 \mathrm{a} \\
(51 ; 24,6)\end{array}$ & $\begin{array}{l}1,15 \text { a } \\
(1,51 ; 0,41)\end{array}$ & $\begin{array}{l}0,11 \mathrm{a} \\
(0,16 ; 0,03)\end{array}$ & $\begin{array}{l}16,10 \mathrm{~b} \\
(26,0 ; 12,0)\end{array}$ & $\begin{array}{l}0,07 \text { a } \\
(0,09 ; 0,02)\end{array}$ \\
\hline UBb20 & $\begin{array}{l}40,00 \mathrm{bc} \\
(48,5 ; 36)\end{array}$ & $\begin{array}{l}1,07 \text { a } \\
(1,32 ; 0,77)\end{array}$ & $\begin{array}{l}0,07 \mathrm{~b} \\
(0,33 ; 0,01)\end{array}$ & $\begin{array}{l}21,30 \mathrm{a} \\
(31,5 ; 15,5)\end{array}$ & $\begin{array}{l}0,04 \mathrm{~b} \\
(0,07 ; 0,01)\end{array}$ \\
\hline UBb11 & $\begin{array}{l}39,60 \text { bc } \\
(52 ; 18,5)\end{array}$ & $\begin{array}{l}0,95 \mathrm{ab} \\
(1,54 ; 0,5)\end{array}$ & $\begin{array}{l}0,08 \mathrm{~b} \\
(0,16 ; 0,02)\end{array}$ & $\begin{array}{l}17,50 \mathrm{a} \\
(27,1 ; 13,8)\end{array}$ & $\begin{array}{l}0,05 \text { a } \\
(0,09 ; 0,01)\end{array}$ \\
\hline UBb15 & $\begin{array}{l}47,25 \mathrm{a} \\
(53,5 ; 30,5)\end{array}$ & $\begin{array}{l}1,12 \mathrm{a} \\
(1,41 ; 0,55)\end{array}$ & $\begin{array}{l}0,11 \mathrm{a} \\
(0,17 ; 0,03)\end{array}$ & $\begin{array}{l}19,20 \mathrm{a} \\
(32,0 ; 13,9)\end{array}$ & $\begin{array}{l}0,08 \mathrm{a} \\
(0,12 ; 0,02)\end{array}$ \\
\hline UBb08 & $\begin{array}{l}46,50 \mathrm{a} \\
(50 ; 35)\end{array}$ & $\begin{array}{l}1,05 \mathrm{ab} \\
(1,36 ; 0,7)\end{array}$ & $\begin{array}{l}0,11 \mathrm{a} \\
(0,16 ; 0,05)\end{array}$ & $\begin{array}{l}16,00 \mathrm{~b} \\
(23,0 ; 14,0)\end{array}$ & $\begin{array}{l}0,06 \text { a } \\
(0,11 ; 0,02)\end{array}$ \\
\hline UBb01 & $\begin{array}{l}39,20 \mathrm{bc} \\
(53 ; 28,7) \\
\end{array}$ & $\begin{array}{l}0,96 \mathrm{ab} \\
(1,41 ; 0,53)\end{array}$ & $\begin{array}{l}0,07 \mathrm{~b} \\
(0,13 ; 0,02)\end{array}$ & $\begin{array}{l}17,60 \mathrm{a} \\
(29,6 ; 13,5)\end{array}$ & $\begin{array}{l}0,05 \mathrm{~b} \\
(0,08 ; 0,01)\end{array}$ \\
\hline UBb18 & $\begin{array}{l}41,75 \mathrm{~b} \\
(51 ; 23)\end{array}$ & $\begin{array}{l}1,06 \text { a } \\
(1,38 ; 0,42)\end{array}$ & $\begin{array}{l}0,11 \text { a } \\
(0,16 ; 0,02)\end{array}$ & $\begin{array}{l}16,00 \mathrm{~b} \\
(19,0 ; 13,5)\end{array}$ & $\begin{array}{l}0,09 \text { a } \\
(0,11 ; 0,02)\end{array}$ \\
\hline UBb04 & $\begin{array}{l}47,50 \mathrm{a} \\
(54,5 ; 38)\end{array}$ & $\begin{array}{l}1,17 \text { a } \\
(1,44 ; 0,73)\end{array}$ & $\begin{array}{l}0,12 \text { a } \\
(0,16 ; 0,07)\end{array}$ & $\begin{array}{l}16,60 \mathrm{~b} \\
(22,0 ; 14,6)\end{array}$ & $\begin{array}{l}0,07 \text { a } \\
(0,10 ; 0,04)\end{array}$ \\
\hline UBb16 & $\begin{array}{l}49,50 \mathrm{a} \\
(53,8 ; 35,5)\end{array}$ & $\begin{array}{l}1,14 \text { a } \\
(1,5 ; 0,81)\end{array}$ & $\begin{array}{l}0,11 \mathrm{a} \\
(0,18 ; 0,04)\end{array}$ & $\begin{array}{l}16,00 \mathrm{~b} \\
(28,0 ; 13,0)\end{array}$ & $\begin{array}{l}0,07 \text { a } \\
(0,11 ; 0,02)\end{array}$ \\
\hline UBb12 & $\begin{array}{l}49,30 \mathrm{a} \\
(58 ; 33)\end{array}$ & $\begin{array}{l}1,20 \text { a } \\
(1,57 ; 0,78)\end{array}$ & $\begin{array}{l}0,09 \text { a } \\
(0,2 ; 0,05)\end{array}$ & $\begin{array}{l}15,50 \mathrm{~b} \\
(24,0 ; 13,0)\end{array}$ & $\begin{array}{l}0,05 \mathrm{~b} \\
(0,07 ; 0,02)\end{array}$ \\
\hline UBb05 & $\begin{array}{l}44,00 \mathrm{a} \\
(56,5 ; 34,5)\end{array}$ & $\begin{array}{l}1.09 a \\
(1,54 ; 0,58)\end{array}$ & $\begin{array}{l}0,09 \text { a } \\
(0,19 ; 0,02)\end{array}$ & $\begin{array}{l}17,30 \mathrm{a} \\
(26,0 ; 12,0)\end{array}$ & $\begin{array}{l}0,05 \mathrm{~b} \\
(0,09 ; 0,01)\end{array}$ \\
\hline
\end{tabular}

Duas ou mais medianas seguidas por uma mesma letra nas colunas não diferem entre si quanto aos respectivos tratamentos utilizadas C/N: aplicação de nitrogênio; S/N: sem aplicação de nitrogênio; S/I: sem aplicação de inoculante

Maior comprimento das raízes foi observado nas plantas que receberam inoculação com as estirpes UB b01, UBb05, UBb11, UBb15 e UBb20, os resultados obtidos com a inoculação com estas estirpes superaram inclusive ao obtido das plantas que receberam N. Os demais tratamentos inoculados e não inoculado apresentaram comprimentos significativamente menores (Tabela 2).

O aumento na produção de fitomassa seca pelas plantas de milho, obtidas neste experimento se deve provavelmente ao efeito das bactérias diazotróficas endofíticas que habitam o interior do tecido vegetal e que podem contribuir de forma mais efetiva para a FBN, já que a troca se faz de forma direta, e há menos competição por fontes de carbono, pois nem todos os micro-organismos são capazes de penetrar no tecido vegetal (BALDANI et al., 1997).

A promoção do crescimento de plantas por rizobactérias também tem sido relacionada à produção de hormônios com giberilinas (HOLL et al., 1988), auxinas (ARAUJO et al., 2005) e ácidos lático e succínico (YOSHIKAWA, 1993). Pseudomonas spp. (fluorescentes) produziu o fitohormônio AIA (ácido indol acético) 
em resposta aos exsudatos de raiz de milho (PAN et al., 1999). Bacillus subtilis produziu AIA e AIB (ácido indolbutírico) em resposta aos exsudatos de raiz de soja (ARAUJO et al., 2005).

Na tabela 3 são apresentados os dados referentes fitomassa fresca das raízes, verificou-se maior acúmulo de fitomassa fresca nas plantas inoculadas com as estirpes UBb04 e UBb18. Diferenças estatísticas significativas foram observadas em relação ao acúmulo de fitomassa seca das raízes (Tabela 2 e Figura 2), plantas inoculadas com as estirpes UBb04, UBb05, UBb11, UBb12, UBb15, UBb16, UBb18 e as que receberam nitrogênio na forma de nitrato de potássio apresentaram maior desenvolvimento. Estes resultados mostram a importância da inoculação com bactérias diazotróficas na produção desta forrageira, principalmente porque o nitrogênio é um dos nutrientes mais limitantes na produção de matéria seca e mais extraídos do solo pelas plantas gramíneas, por ser componente crucial de compostos orgânicos essenciais à vida das plantas, como aminoácidos e proteínas, ácidos nucléicos, hormônios e clorofila (FRANÇA et al., 2007).

Tabela 3: Média e desvio Padrão da variável fitomassa fresca da raiz para plantas de plantas de milho transgênico cv DKB 390PRO2, submetidas a diferentes tratamentos.

\begin{tabular}{|c|c|c|c|c|c|c|c|c|c|c|c|c|c|}
\hline \multirow[b]{2}{*}{ Variável } & & \multicolumn{12}{|c|}{ Tratamentos } \\
\hline & & 1 & 2 & 3 & 4 & 5 & 6 & 7 & 8 & 9 & 10 & 11 & 12 \\
\hline $\begin{array}{l}\text { Fitomassa } \\
\text { raiz }\end{array}$ & fresca da & $\begin{array}{l}0,61 \\
(0,18) \\
d\end{array}$ & $\begin{array}{l}0,63 \\
(0,16) \\
C d\end{array}$ & $\begin{array}{l}0,56 \\
(0,13) \\
\mathrm{Cd}\end{array}$ & $\begin{array}{l}0,69 \\
(0,17) \\
\text { bcd }\end{array}$ & $\begin{array}{l}0,71 \\
(0,18) \\
\text { bcd }\end{array}$ & $\begin{array}{l}0,72 \\
(0,20) \\
\text { Bcd }\end{array}$ & $\begin{array}{l}0,78 \\
(0,17) \\
\text { Bcd }\end{array}$ & $\begin{array}{l}0,89 \\
(0,21) \\
A\end{array}$ & $\begin{array}{l}0,86 \\
(0,21) \\
a\end{array}$ & $\begin{array}{l}0,76 \\
(0,19) \\
\text { abcd }\end{array}$ & $\begin{array}{l}0,51 \\
(0,09) \\
c d\end{array}$ & $\begin{array}{l}0,52 \\
(0,20) \\
B c d\end{array}$ \\
\hline
\end{tabular}

Duas ou mais média seguidas por uma mesma letra na linha não diferem entre si quanto aos respectivos tratamentos utilizados: T1: UBb11; T2: UBb01; T3: UBb20; T4: Testemunha sem fornecimento de N e sem inoculação; T5: UB b15; T6: UCCB b08; T7: Testemunha com fornecimento de N e sem inoculação; T8: UBb18; T9: UBb04; T10: UBb10; T11: UBb12; T12: UBb05.

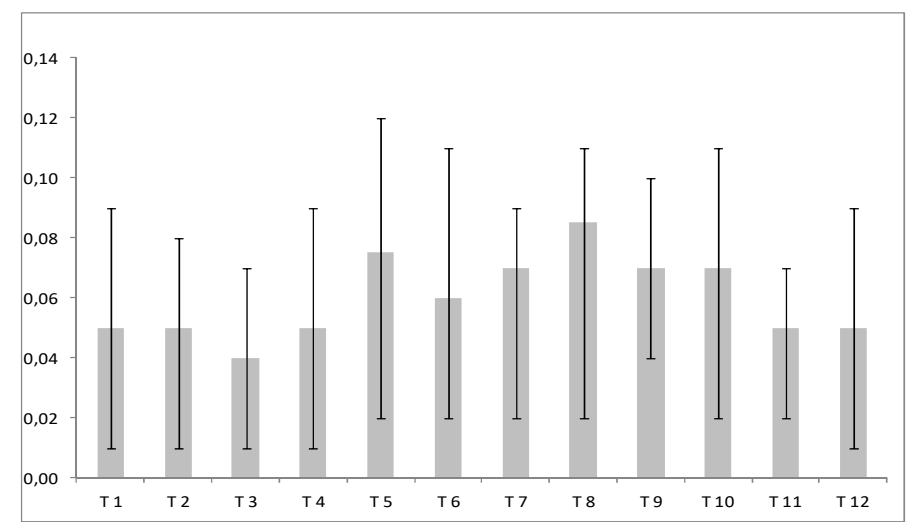

Figura 2: Mediana, máximo e mínimo para variável fitomassa seca da raiz de plantas de milho cv DKB 390PRO2, por tratamento: T1: UBb11; T2: UBb01; T3: UBb20; T4: Testemunha sem fornecimento de N e sem inoculação; T5: UBb15;

T6: UBb08; T7: Testemunha com fornecimento de N e sem inoculação; T8: UBb18; T9: UBb04; T10: UBb10; T11: UBb12; T12: UBb05.

\section{Experimento 2}

A tabela 4 apresenta os resultados obtidos em casa-de-vegetação, verificou-se que não houveram diferenças estatísticas significativas quando foram avaliados os comprimentos da parte aérea e das raízes de milho. Em relação a fitomassa fresca e seca da parte aérea observou-se que plantas que receberam inoculação com a s bactérias UBb04, UBb15 e UBb16 apresentaram desenvolvimento superior as que receberam nitrogênio e a testemunha (Tabela 4). 
Tabela 4: Média \pm Desvio Padrão ou Mediana (máximo; mínimo) das variáveis comprimento e fitomassa fresca e seca da parte aérea e fitomassa seca da raiz de plantas de milho transgênico cV DKB 390PRO2 submetidas a diferentes tratamentos.

\begin{tabular}{|c|c|c|c|c|c|c|}
\hline \multirow[t]{2}{*}{ Variáveis } & \multicolumn{5}{|l|}{ Tratamentos } & \multirow[t]{2}{*}{ Valor $\mathbf{p}$} \\
\hline & 1 & 2 & 3 & 4 & 5 & \\
\hline Comprimento das folhas & $\begin{array}{l}88,2 \pm 19,6 \\
a b^{(1)}\end{array}$ & $\begin{array}{l}73,3 \pm 10,2 \\
\mathrm{Ab}\end{array}$ & $\begin{array}{l}89,6 \pm 16,4 \\
\mathrm{Ab}\end{array}$ & $\begin{array}{l}100,7 \pm 10,7 \\
\text { A }\end{array}$ & $\begin{array}{l}65,4 \pm 12,9 \\
\mathrm{Ab}\end{array}$ & 0,0022 \\
\hline Comprimento das raízes & $\begin{array}{l}83,4 \pm 16,5 \\
A\end{array}$ & $\begin{array}{l}73,4 \pm 8,8 \\
A\end{array}$ & $\begin{array}{l}72,0 \pm 10,4 \\
\text { A }\end{array}$ & $\begin{array}{l}78,5 \pm 6,99 \\
a\end{array}$ & $\begin{array}{l}68,0 \pm 1, .8 \\
A\end{array}$ & 0,1745 \\
\hline Fitomassa fresca da parte aérea & $\begin{array}{l}41,0(56,3 ; 9,7) \\
\mathrm{ab}\end{array}$ & $\begin{array}{l}14,1(31,8 ; 6,7) \\
\mathrm{Ab}\end{array}$ & $\begin{array}{l}38,2(49,7 ; 15,1) \\
\mathrm{Ab}\end{array}$ & $\begin{array}{l}44,0(78,0 ; 26,4) \\
\text { B }\end{array}$ & $\begin{array}{l}8,3(17,8 ; 2,4) \\
\text { A }\end{array}$ & $0,004^{*}$ \\
\hline Fitomassa fresca das raízes & $\begin{array}{l}28,4(48,3 ; 3,5) \\
\text { abc }\end{array}$ & $\begin{array}{l}5,4(18,9 ; 1,7) \\
\mathrm{Ab}\end{array}$ & $\begin{array}{l}53,9(73,1 ; 19,9) \\
\text { C }\end{array}$ & $\begin{array}{l}31,4(72,4 ; 26,4) \\
\text { Bc }\end{array}$ & $\begin{array}{l}3,2(8,1 ; 1,0) \\
\mathrm{A}\end{array}$ & $<0,001^{*}$ \\
\hline Fitomassa seca da parte aérea & $\begin{array}{l}6,1(9,3 ; 1,4) \\
\mathrm{Ab}\end{array}$ & $\begin{array}{l}2,03(4,6 ; 1,3) \\
\mathrm{Ab}\end{array}$ & $\begin{array}{l}5,3(7,5 ; 2,2) \\
\mathrm{Ab}\end{array}$ & $\begin{array}{l}7,0(12,8 ; 3,4) \\
\mathrm{B}\end{array}$ & $\begin{array}{l}1,1(2,4 ; 0,5) \\
\text { A }\end{array}$ & $0,002 *$ \\
\hline Fitomassa seca de raízes & $\begin{array}{l}7,1(13,7 ; 1,0) \\
\mathrm{Ab}\end{array}$ & $\begin{array}{l}1,8(5,8 ; 0,9) \\
\mathrm{Ab}\end{array}$ & $\begin{array}{l}9,3(15,3 ; 3,6) \\
\text { B }\end{array}$ & $\begin{array}{l}7,4(15,1 ; 5,5) \\
\text { B }\end{array}$ & $\begin{array}{l}1,2(3,6 ; 0,6) \\
\mathrm{A}\end{array}$ & $0,003^{*}$ \\
\hline
\end{tabular}

(1) Para cada variável analisada, duas médias ou medianas seguidas de letras minúsculas distintas indicam diferença estatística significativa entre os tratamentos, considerando $5 \%$ de significância. * Teste não paramétrico de Kruskall Wallis (mediana, máximo e mínimo) 1: UBb16; 2: Testemunha sem fornecimento de N e sem inoculação; 3: UBb15; 4: UBb04; 5: Testemunha com fornecimento de $\mathrm{N}$ e sem inoculação.

Verificou-se que as estirpes UBb04, UBb15 e UBb16 favoreceram o desenvolvimento radicular e da parte aérea (tabela 4), sabe-se que as bactérias promotoras do crescimento vegetal possuem efeito benéfico no desenvolvimento das plantas (MANTELIN et al., 2004), mas o mecanismo pelo qual as bactérias produzem este efeito é complexo e resulta da combinação de vários aspectos que estão relacionados com a nutrição mineral, o metabolismo do carbono e o desenvolvimento radicular (EL-KOMY et al., 2003; MANTELIN et al., 2004), razão pela qual muitas vezes não é possível explicar como estas bactérias interferiram no desenvolvimento das plantas inoculadas. Provavelmente as bactérias utilizadas neste experimento foram capazes de se adaptar ao ambiente e colonizar mais rapidamente a rizosfera. Escassos são os estudos realizados com a finalidade de explicar os mecanismos de sobrevivência e colonização da rizosfera pelos micro-organismos. Um melhor entendimento dos parâmetros que regulam a colonização da raiz pode ajudar a melhorar a eficiência dos inoculantes sob diferentes condições ambientais e estimular a aplicação em grande escala inoculantes contendo estes microrganismos (DOBBELAERE et al., 2002).

\section{CONCLUSÕES}

De acordo com a metodologia utilizada e pelos resultados obtidos pode concluir-se que: - em condições estéreis as estirpes UCCB b04, UCCB b05, UCCB b08, UCCB b12, UCCB b15, UCCB b16 promoveram o crescimento de plantas de milho; - as estirpes UCCB b04, UCCB b15, UCCB b16, em condições de casa de vegetação favoreceram o desenvolvimento das plantas de milho, superando inclusive as plantas que receberam nitrogênio.

\section{REFERÊNCIAS}

ARAUJO, F. F.; HENNING, A.; HUNGRIA, M. A..

Phytohormones and antibiotics produced by Bacillus subtilis and their effects on seed pathogenic fungi and on soybean root development. World Journal of Microbiology \& Biotechnology, Dordrecht, v. 21, p.1639-1645, 2005.

BALDANI, J. I.; CARUSO, L.; BALDANI, V. L. D.; GOI, S. R.; DÖBEREINER, J.. Recent advances in BNF with non-legume plants. Soil Biology \& Biochemistry, n.5/6, v.29, p.911-922, 1997.

BOBATO, A.. Índice nutricional do nitrogênio: uma ferramenta para o diagnóstico do estado nutricional da cultura do milho. Dissertação (Mestrado em Ciência do Solo) - Universidade Federal do Paraná, Curitiba, 2006. 
BORACIN, M. A.; KOZUSNY-ANDREANI, D. I.; ANDREANI JUNIOR, R.. Efeito de bactérias rizosféricas e fertilizantes no enraizamento de violeta africana. Revista da Universidade Vale do Rio Verde, Três Corações, v.14, n.1, p.366-375, 2016.

DIDONET, A. D.; LIMA, O. S.; CANDATEN, A. A.; RODRIGUES, O.. Realocação de nitrogênio e de biomassa para os grãos, em trigo submetido a inoculação de Azospirillum. Pesquisa agropecuária brasileira, v.35, n.2, p.401-411, 2000.

DOBBELAERE, S. A.; CROONENBORGHS, A.; THYS, A.; PTACEK, D.; OKON, Y.; VANDERLEYDEN, J.. Effect of inoculation with wild type Azospirillum brasiliense: A irakense strains on development and nitrogen uptake of spring wheat and grain maize Biology and Fertility of Soils. 36 ed. 2002.

DÖBEREINER, J.; BALDANI, J. I.; BALDANI, V. L. D.. Como isolar e identificar bactérias diazotróficas de plantas não leguminosas. Brasília: Embrapa-CNPAB, 1995.

EL-KOMY, H. M.; HAMDIA, M. A.; EL-BAK, I.. Nitratte reductase in wheat plants grown under water stress and inoculated Azospirillum spp. Biological Plant. v.46, p.281287, 2003.

FIGUEIREDO, M. V. B.; BURITY, H. A.; STAMFORD, N. P.; SANTOS, C. E. R. S.. Microrganismos e agrobiodiversidade: o novo desafio para a agricultura. Guaíba: Agro livros, 2008.

FRANÇA, A. F. S.; BORJAS, A. L. R.; OLIVEIRA, E. R.; SOARES, T. V.; MIYAGI, E. S.; SOUSA, V. R.. Parâmetros nutricionais do capim-tanzânia sob doses crescentes de nitrogênio em diferentes idades de corte. Ciência Animal Brasileira, v.8, p.695-703, 2007

HOLL, F. B.; CHANWAY, C. P.; TURKINGTON, R.; RADLEY, R. A.. Response of crested wheatgrass (Agropyron crystatum L.), perennial ryegrass (Lolium perenne) and white clover (Trifolium repens L.) toinoculation with Bacillus polymyxa. Soil Biology and Biochemstry, London, v.20, p.19-24, 1988.

HUNGRIA, M. A.; CAMPO, R. J.; SOUZA, E. M.; PEDROSA, F. $O$.. Inoculation with selected strains of Azospirillum brasilense: lipoferum improves yields of maize and wheat in Brazil. Plant and Soil, v.331, p.413-425, 2010.

KOZUSNY-ANDREANI, D. I.; AGIADO, J. C.; ANDREANI JUNIOR, R.. Efeito de bactérias rizosféricas sobre odesenvolvimento da cenoura. Revista da Universidade Vale do Rio Verde, v.12, n.1, p.211-220, 2014.
MARIANO, R. L. R.; KLOEPPE, R. J. W.. Método alternative de biocontrole: resistência sistêmica induzida por rizobactérias Revisão Anual de Patologia de Plantas, v.8, p.121-137, 2000.

MOREIRA, F. M. S.; SIQUEIRA, J. O.. Microbiologia e Bioquímica do Solo. 2 ed. Lavras: UFLA, 2006.

NANDAKUMAR, R.; BABU, S.; VISWANATHAN, R.; RAGUCHANDER, T.; SAMIYAPPAN, R.. Induction of systemic resistance in rice against sheath blight disease by Psudomonas fluorescens. Soil Biology and Biochemical, v. 33, p.603-612, 2001

PAN, B.; BAY, Y. M.; LEIBOVITCH, S.; SMITH, D. L.. Plantgrowth promoting rhizobacteria and kinetin as ways to promote corn growth and yield in a short growing seasonarea. European Journal of Agronomy, Amsterdan, v.11, p.179-186, 1999.

RAMAMOORTHY, V.; VISWANATHAN, R.; RGGUCHANDER, T.; PRACKASAM, V.; SAMIYAPPAN, R.. Induction of systemic resistance by plant growth promoting rhizobacteria $\mathrm{n}$ crop plants against pests and diseases. Crop Protection, v.20, p.120, 2001.

RODRIGUEZ, H.; FRAGA, R.. Phosphate solubilizing bacteria and their role in plant growth promotion. Biotechnology Advances, v.17, p.310-339, 1999.

SALA, V. M. R.; SILVEIRA, A. P. D.; CARDOSO, E. J. B. N.. Bactérias diazotrófocas associadas a plantas nãoleguminosas. In: SILVEIRA, A. P. D.; FREITAS, S. S.. Microbiota do solo e qualidade ambiental. Campinas: São Paulo, 2007. p.312.

SCHLINDWEIN, G.; VARGAS, L. K.; LISBOA, B. B.; AZAMBUJA, A. C.; GRANADA, C. E.; GABIATTI, N. C.; PRATES, F.; STUMPF, R.. Influência da inoculação de rizóbios sobre a germinação e o vigor de plântulas de alface. Ciência Rural, v.38, p.658-664, 2008 .

TORIBIO-JIMÉNEZ, J.; RODRÍGUEZ-BARRERA, M. A.; HERNÁNDEZ-FLORES, G.; RUVALCABA-LEDEZMA, L. C.; CASTELLANOS-ESCAMILLA, M.; ROMERO-RAMÍREZ, Y.. Isolation and screening of bacteria from Zea mays plant growth promoters. Revista Internacional de Contaminación Ambiental, v. 33, p.143-150, 2017.

YOSHIKAWA, M.. Succinic and latic acids as plant growth promoting compounds produced by rhizosphere Pseudomonas putida. Canadian Journal of Microbiology, Ottawa, v.39, p.1150-1154, 1993.

A CBPC - Companhia Brasileira de Produção Científica (CNPJ: 11.221.422/0001-03) detém os direitos materiais desta publicação. Os direitos referem-se à publicação do trabalho em qualquer parte do mundo incluindo os direitos às renovações, expansões e disseminacões da contribuicão, bem como outros direitos subsidiários. Todos os trabalhos publicados eletronicamente poderão posteriormente ser publicados em coletâneas impressas sob coordenação da Sustenere Publishing, da Companhia Brasileira de Produção Científica e seus parceiros autorizados. Os (as) autores (as) preservam os direitos autorais, mas não têm permissão para a publicação da contribuição em outro meio, impresso ou digital, em português ou em tradução. 